\title{
Social Impact Bonds in Bangladesh: Saving a Million Life Years and Healthcare Costs
}

\author{
Deena Mehjabeen ${ }^{1}$, ASM Amanullah PhD $^{2}$ \\ PG Scholar, Faculty of Medicine and Health, Sydney School of Public Health, University of Sydney, Australia ${ }^{1}$ \\ Professor, Department of Sociology, Dhaka University, Bangladesh ${ }^{2}$
}

\begin{abstract}
The paper helps to answer research questions to establish the 'Save a Million' (SaM) project using Disability Adjusted Life Years (DALYs) information. The research questions are categorised into the three stakeholder groups such as savings program providers; institutional cost-bearers such as health insurance companies and hospitals; and finally, potential promoters involving health campaigners and the media in Bangladesh. The findings indicate that Bangladesh is a suitable jurisdiction for setting up Social Impact Bonds (SIBs) and carrying out the 'Save a Million' project in order to reduce out-of-pocket healthcare costs and save lives.
\end{abstract}

Keywords: ‘Social Impact Bonds (SIB)', 'Disability-Adjusted Life Years (DALY)', Bangladesh, Public Health

\section{INTRODUCTION}

The 'Save a Million' project proposes to save a million years of life as measured by Disability-Adjusted Life Years, (DALYs) and a million dollars in healthcare costs within 10 years across multiple jurisdictions. This is done through enabling multiple Social Impact Bonds (SIBs) and multi-SIB funds or from multiple stakeholders known as 'Outcome Funds.' SIBs involve a starting proposal of savings that is equally shared (50/50) between cost-bearers and savings programmers.

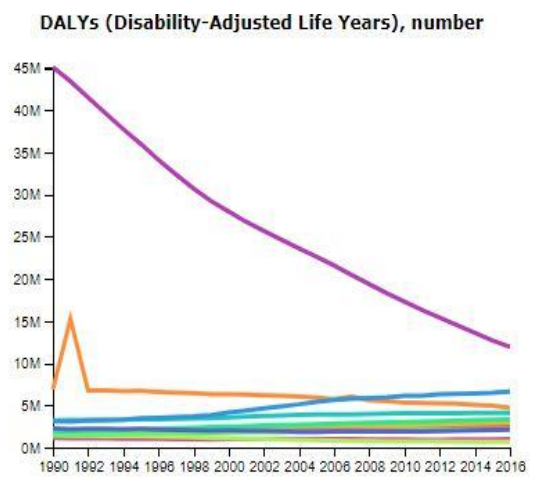

Legend

- Bangladesh, Both sexes, All Ages, Diabetes, urogenital, blood, and endocrine diseases

- Bangladesh, Both sexes, All Ages, Communicable, maternal, neonatal, and nutritional diseases

- Bangladesh, Both sexes, All Ages, Cirrhosis and other chronic liver diseases

- Bangladesh, Both sexes, All Ages, Neoplasms

- Bangladesh, Both sexes, All Ages, Injuries

" Bangladesh, Both sexes, All Ages, Musculoskeletal disorders

- Bangladesh, Both sexes, All Ages, Digestive diseases

= Bangladesh, Both sexes, All Ages, Neurological disorders

- Bangladesh, Both sexes, All Ages, Mental disorders

- Bangladesh, Both sexes, All Ages, Other non-communicable diseases

- Bangladesh, Both sexes, All Ages, Cardiovascular diseases

- Bangladesh, Both sexes, All Ages, Chronic respiratory diseases

Fig.1: Graph showing the Disability-adjusted Life Years in numbers for all diseases in Bangladesh from 2007-2016 [2] 


\title{
International Advanced Research Journal in Science, Engineering and Technology
}

\author{
Vol. 6, Issue 6, June 2019
}

The process is cause-neutral and all potential savings program providers are to be invited into the project. With a population of 166 million, Bangladesh has about 45 million poor people struggling to pay for healthcare. Currently, there is no Universal Health Coverage (UHC) in Bangladesh although an endeavor is being made to establish UHC in the country by 2030 [1]. In the meantime, Save a Million (SaM) project can help to reduce healthcare costs. For this project, a viable jurisdiction is a country with $>20$ million DALYs lost. In Bangladesh, during the last decade 2007 2016, 476,369,374.59 DALYs were lost due to communicable, non-communicable diseases, mental disorders and injuries including road traffic accidents [2].

\section{METHODOLOGY}

'Save a Million' project is cause-neutral, meaning no specific disease is considered when estimating the years of life saved. The intention is to find health interventions focusing on preventing or treating diseases that is responsible for significant numbers of DALYs so that all savings program providers can be invited to participate. The method is online research. In most cases, the websites are not known in advance and will be different for most jurisdictions. Some information on savings programs was found in academic health papers, though most information was from government websites and non-governmental organizations reports. To find DALY data, a website on Global Burden of Disease (GBD) data for every country: "http://ghdx.healthdata.org/gbd-results-tool" was used. Data on the three stakeholder groups were gathered in order to curate public health information from government websites, official reports, nongovernmental organization websites, annual progress reports, journal publications and newspaper articles. Potential Savings Program Providers (SPP) were selected based on lives or DALYs saved; the estimated required expenditure; and cost savings or cost effectiveness. Institutional Cost-Bearers (CB) were based on incidence costs for emergency and accidents in public (government-funded) hospitals; whether the government or patients were paying for ambulance call-out; public hospital in-patient costs; medical appointment costs; pharmaceutical costs; discount repayment scheme; and private and community Health Insurance System (HIS). 'Save a Million' Supporters (SS) were chosen based on traditional social promoters; health organizations and peak bodies; community representatives; advocacy and financial groups and philanthropists.

\section{FINDINGS}

It was found that six savings programs received significant financial aids and research advances; and also, a large proportion of life years (DALYs) were involved. These were cervical cancer screening, family planning, maternal and child care, safe roads, tuberculosis control program, malaria and AIDS prevention and diabetes control program.

There are 17,686 diagnosed cases and 10,362 deaths per year in Bangladesh [3]. For cervical cancer screening, in 2017, it was found that the crude incidence rate of cervical cancer was 12.4 per 100,000 women [4]. By 2025, this number is estimated to rise to over 31,000 new cases and 18,000 deaths per year. Between the years 1990 to $2016,86601.94$ DALYs were lost for females aged 30-69 years due to cervical cancer. In low-income countries like Bangladesh, screening once in a lifetime during 2015-2024, leads to 1.4 million cases and 968,000 cervical cancer deaths being averted [5]. Full time screening program costs $\$ 87,388$ US dollars annually for slum and rural areas of Bangladesh and here, cost-effectiveness (net cost per DALY averted) is found to be USD 255 for a one-time screening at 35 years. Each round of brachytherapy treatment costs Tk. 2,000 at public hospitals and between Tk. 10,000 (USD 118) to Tk. 12,000 (USD 142) at the private hospitals. Screening and early detection could reduce this number [6].

A potential savings program provider is one whose program saves lives and costs. Non-profit organizations such as Cancer Pratirodh Gobeshona Kendra (Cancer Prevention Research Center), Gyne-Oncology Society of Bangladesh, Oporajita (Society for Survivor), Public Health Foundation of Bangladesh, Community Oncology Foundation of Bangladesh, The Blue Sky Charitable Foundation, Cancer Awareness Foundation of Bangladesh, HOPE Foundation for Women and Children, National Institute of Cancer Research and Hospital and Bangabandhu Sheikh Mujib Medical University (BSMMU) Hospital are examples of major savings program providers for cervical cancer screening in Bangladesh. It is believed that by providing local and community hospitals in rural areas with the essential medical facilities and expertise, these can participate as a potential savings program provider [7].

A major portion of the healthcare interventions and associated costs in Bangladesh is for mother and child health. Maternal and gynaecological disorders contribute to 307, 417.83 and 159,978.49 DALYs in females aged 15-49 years old. Neonatal disorder in male and female early and late neonates is 4081462.08 DALYs. Between the years of 1990 to 2016, congenital birth defects contributed 626583.64 DALYs in children aged 9 years and younger [2].

An example of a health intervention is the BlueStar Bangladesh Program (BSP) launched in 1998. By providing oral contraceptives, condoms, injectable, Copper T, emergency contraceptive pills and clean delivery kits, the program 


\section{International Advanced Research Journal in Science, Engineering and Technology}

Vol. 6, Issue 6, June 2019

plays a role in family planning, reproductive health, maternal and newborn health. It was estimated that in 2012, BlueStar Bangladesh Program served 1,236,747 people and 10,048 DALYs was averted in terms of maternal mortality and morbidity, child mortality and unsafe abortions by 2013 [8]. Another prominent non-profit health organization is 'Grameen Kalyan' which is also known as 'Grameen Health', that provides outpatient services regarding safe motherhood, delivery and neonatal care to 5.2 million people as of August, 2018 [9].

Many of the 'Building Resources Across Communities' (BRAC) projects are related to maternal health. In 2017, it was found that 120 million people received the healthcare services, 2 million pregnant women received counselling regarding breastfeeding and diet during pregnancy, 714,770 pregnant women received antenatal care and 15 million women were counselled by the village community health workers on modern contraceptive methods. The estimated expenditure of BRAC for setting up these projects was about US\$550 million [10].

Gonoshasthaya Kendra (GK, or People's Health Centre) is another key healthcare provider that can also act as a potential savings program provider. GK implemented Comprehensive Primary Health Care (CHPC) program that provides services to about 1.2 million people. With the help of this program, IMR (Infant Mortality Rate) came down to 15 per 1000 live births, neonatal mortality was lowered to 10 per 1000 live births and MMR (Maternal Mortality Ratio) was 186 per 100,000 live birth which is $42 \%$ lower than the national average. Gonoshasthaya Kendra reports that the annual unit cost of treating patients is around US\$ 1.00 per person while government spent US\$ 4.00 per person with much lower achievement [11].

Two other potential savings program providers are the Concerned Women For Family Development (CWFD) [12] and Sajida Foundation Health program that provides clinic based maternal and child health services to a combined population of about 4 million in Bangladesh to decrease maternal and child mortality. In 2016, Sajida Foundation had an annual budget of 555M USD [13]. National Family Planning Program (NFPP, 2016-2020) implemented by the Ministry of Health and Family Welfare (MOHFW) can reduce 22,119,585 DALYs. NFPP estimated the costs saved to individual households and national budgets due to abortions and infant and maternal deaths averted will be USD $18,832.41$. The MOHFW estimated that a total of US $\$ 1377.36$ million will be required to adequately implement NFPP activities from 2016 to 2020, rising from US\$227.73 million in 2016 to US\$327.67 million in 2020 [14].

In Bangladesh, the World Health Organization (WHO) estimates that road traffic accidents causes 21,316 deaths which is 13.6 per 100,000 people. Here, in 2016, 1,437,009 DALYs lost due to road traffic injuries could have been averted. Using DALY data from neighbouring countries of Bangladesh, such as India and Nepal, road safety interventions like speed limits, preventing drink-driving, seatbelt use and motorcycle and bicycle helmet use showed that 238 DALYs were saved per million population annually. Cost-effectiveness of road safety interventions like speed limits, preventing drink-driving, seatbelt use and motorcycle and bicycle helmet use was around US\$ 1382 in India and Nepal. Data from 2007 shows that US\$ 1.5 million was spent in Bangladesh as part of official assistance and foreign funds for road safety interventions [15]. Presently, the national financial loss due to road traffic accidents is reported to be at least Tk. 5,000 crore which is US\$ 850 million per annum and around 2\% of the Gross Domestic Product (GDP). A speed management program implemented by 'Centre for Injury Prevention and Research Bangladesh' (CIPRB) in partnership with 'Safe Crossings' from the Netherlands proved to be very cost-effective, with less than US\$ 100 cost per DALY saved. For Bangladesh, cost-effectiveness data from 2010 showed that approximately US\$ 79 per DALY has been averted from traffic enforcement and US\$11 per DALY was averted from implementing speed bumps [16].

One example of potential savings program providers for safe roads is BRAC that has developed projects like 'Surakkha (Protection) road safety and defensive-driving program', 'Community Road Safety Program (CRSP)' and 'Safe Roads for Women and Girls'. Another example is Centre for Injury Prevention and Research Bangladesh (CIPRB) that is working with 'Safe Crossings' in the Netherlands. Nirapad Sarak Chai (We demand Safe Road) and AIP Foundation for Road Safety are Non-Governmental Organizations (NGOs) that have been working with Government of Bangladesh (GOB) and the media for road safety awareness. The Ministry of Communications, Roads and Railway Division implemented the National Road Safety Action Plan that was originally initiated in 1996 and also between 2002 and 2004. This Plan was supported by the World Bank, Asian Development Bank and Bangladesh Road Traffic Authority (BRTA) [17]. Ministry of Health and Family Welfare (MOHFW), community healthcare clinics, regional and district hospitals, insurance companies, rehabilitation centres and counselling services are potential savings program providers that are present in the country but not yet actively involved in the process of establishing savings programs.

In Bangladesh, in 2016, it was found that 545,758.96 DALYs lost due to tuberculosis (TB) can be saved. National Tuberculosis Control Program data from 2014, showed around 51 per 100,000 people died of TB. BRAC TB control programme screened 1.3 million people and treated 149,228 TB patients. The current six months (Directed Observed Treatment Short course, DOTS) regimen of oral treatment was more cost-effective with an average US\$ 16.17 and a 


\title{
International Advanced Research Journal in Science, Engineering and Technology
}

\author{
Vol. 6, Issue 6, June 2019
}

lower incremental cost-effectiveness ratio (ICER US\$1,220) than the four months treatment for multi-drug resistant TB (US\$ 16.20 average) [18]. From the 2016 data, 121056.31 DALYs lost due to malaria and Human Immunodeficiency Virus/Acquire Immunodeficiency Syndrome (HIV/AIDS) can be averted by control and treatment programs. 18,900 malaria cases were treated by BRAC malaria prevention and treatment programs. Malaria is treated with WHO recommended artemisin-combined therapy (ACT). The cost is under \$150 per Disability-Adjusted Life-Year (DALY) when drug resistance is high and over $\$ 150$ per DALY when drug resistance is low. Other interventions like implementation of environmental control program shows a cost-effectiveness of US\$858 per death and there is a costeffectiveness of US\$254 to $\$ 3437$ per death averted for insecticide treated mosquito net [19]. For HIV/AIDS, in all of South East Asia, on average 267.9 DALYs were averted with a combination of interventions such as mass media campaign, sex education of sex workers, school based education, prevention of mother to child transmission, counselling and antiretroviral therapy. Average cost effectiveness ratio was US\$ 5904 per DALY averted [20].

1,033,181.12 DALYs were responsible for diabetes mellitus in 2016 that can be averted. Non-communicable Disease (NCD) programmes from BRAC screened 153,930 people for diabetes mellitus and hypertension. Diabetic Association of Bangladesh and Bangladesh Institute of Research and Rehabilitation for Diabetes, Endocrine \& Metabolic Disorders (BIRDEM) are also working towards diabetes control. In South East Asia, retinopathy screening \& glycaemic control for patients with diabetes has shown a cost-effectiveness of less than US\$ 950 per DALY averted [21].

In all public health facilities patients pay a 5 Taka (about 0.059 USD) registration fee and then all treatment and drugs are free. In-patients are provided with food paid for directly by government at 75 Taka (about 0.89 USD) per meal [22]. If the patient chooses private room at government hospitals, then he/she or the family has to pay for the doctor's fees, diagnostic tests, drugs, cabin fee, meals and tips to cleaners, female attendants and ward boys. In Bangladesh, out-ofpocket (OOP) expenditure constitutes a major portion, about 63 to $67 \%$ of health finance. Total consumption in the poorest quintile (Tk. 13,529 or USD 60) is less than half (Tk. 29,908 or USD 354) of the total average consumption. Clear inequity is seen in healthcare payments between the poorest and the richest quintiles [23].

Both public and private hospitals have ambulance services and payment is done by patients or their family. Since most public hospitals have inadequately equipped ambulances and private hospitals cannot be afforded by all, patients often prefer ambulances dispatched from 24 hours private ambulance companies [24]. Lower income patients go to NGOs like Gonoshasthaya Kendra for subsidized or free ambulances. A privately owned non-air conditioner ambulance within Dhaka city costs between Tk. 700 (approximately USD 8) and Tk. 3,000 (approximately USD 35) on average depending on the distance, time of the day and vehicle's condition. Private hospitals, with modern ambulances, usually costs around Tk. 8,000 to Tk. 10,000 (approximately USD 94 to 118) per trip. Ambulance costs are included in the overall bill for treatment [25].

In public hospitals, general beds are free of cost to patients. If patients choose a private cabin, they have to pay for investigation cost, medicine, surgery, seat (bed) rent, service charge, transport and tips (comprised about $70 \%$ of extra payment) to ward boys, cleaners and other lower-class employees [26]. For example, one hospital was charging 75 Taka (about USD 0.89) per bed per day plus food at 125 Taka (1.48 USD) per day. Private cabins were also available at 150 or 200 Taka (1.78 or 2.37 USD) per day plus food at 150 Taka or 1.78 USD per day. Private beds for operations were available at 500 Taka (5.92 USD) per day and private rooms for operations were also available at 500-2000 Taka (5.92-23.68 USD) per day, depending on whether the surgery was major or minor [22]. Patients often pay with the help of NGOs and health insurance, if unable to pay on their own. Mean expenditure for public hospitals was BDT 8000 or USD 94 approximately [26].

Patients pay for medicine and pharmaceuticals at public and private hospitals. For the poorest of the patients, medicine is provided for free [27]. There is no discount repayment scheme unless it is a non-profit hospital or covered by health insurance [28]. Primary care outpatient drug use in various public hospitals, community clinic and private pharmacy showed an average cost of 712 BDT or 8.43 USD. In 2010, budget allocation by the government for drugs in the public sector was very low, around 0.36 USD per person per year. Ministry of Health and Family Welfare (MOHFW) funds hospitals up-front [22]. In Bangladesh, total health expenditure was $2.9 \%$ of gross domestic product, one of the lowest allocations in the world. In 2015, it was found that out-of-pocket (OOP) expenditures represented $67 \%$ of total health expenditure, which is one of the highest proportions in the world [29].

Directorate General of Health Services (DGHS) is one of the agencies of the Ministry of Health and Family Welfare of Bangladesh with primary hospital budget. The Ministry of Local Government (MOLG) provides a significant portion of health services, as it has responsibility for providing public health services, waste management and water supply in urban (city corporation and municipalities) and rural areas [30]. The budget (2018-19) allocated for health sector is Tk. 233 billion, which approximately 2 billion USD. This is only about 5\% of the total budget and below WHO guidelines of $15 \%$ of the total budget [31]. 


\title{
International Advanced Research Journal in Science, Engineering and Technology
}

\author{
Vol. 6, Issue 6, June 2019
}

The Ministry of Finance (MOF) refunds health costs only to government employees in the form of monthly medical allowances [32]. Local Government Engineering Department (LGED) of the Ministry of Local Government, Rural Development and Cooperatives, the Ministry of Food and Disaster Management, Ministry of Agriculture, Ministry of Fisheries and Livestock, Ministry of Water Resources, Ministry of Environment and Forestry, Ministry of Women and Children Affairs, Ministry of Education, and Ministry of Social Welfare all contribute to public health costs [30]. There is a private health insurance system in Bangladesh. An example is the 'Pragati Life Insurance Limited (PLIL) Health Insurance and Hospitalization Plan.' By paying a small premium in advance, the client is covered for hospital treatment expenses including private rooms, physicians or surgeons' consultation, medical investigations, anaesthesia, medicine, use of labour room, post-operative care, intensive care facility and blood transfusion. The maximum benefit plan is estimated to be above BDT 50,000 (USD 592) yearly [33].

A community micro-insurance organization, 'Grameen Kalyan', supported by Grameen Bank provides health microinsurance especially for the poor. Non-members of Grameen Bank pay US \$4.28 and members have to pay US \$2.85 as premium. Hospitalization compensation is up to USD 25. The plan provides free preventive care, family planning, and health education services and discounts on medicine and laboratory tests. The health insurance scheme covers six members of the family [9]. Based on socio-economic status, Gonoshasthaya Kendra's Health Insurance Scheme helps insured people pay premiums and co-payments for sustainable health services. Benefits include inpatient coverage for the family, maternity benefits up to US\$675, and subsidized drugs depending on socio-economic status. The premium is approximately US\$0.1 to US\$1 as estimated in 2000 [11]. 'Save a Million' promoters are classified as the media, health advocates and convenors who encourage and support the project. 'The Daily Star' is a leading English daily newspaper in Bangladesh, with a circulation estimated to be around forty-one thousand as of 2014 and aims to provide news and information to Bangladeshi citizens and beyond. The newspaper plays an important role in reducing the maternal mortality ratio and raise awareness by increasing the number of published articles from 4 in 2008 to 217 in 2012. This helped to meet the Millennium Development Goals (MDG) for improving maternal health in low-income countries [34].

The largest selling Bengali newspaper in Bangladesh, providing news and participating in campaigns regarding health, education and poverty alleviation is the 'Prothom Alo'. This newspaper has a readership of around 9.6 million. Online portal received almost 1.6 million visitors from 200 countries with 60 million page view per month. 'Prothom Alo' has been carrying out awareness raising campaigns on HIV/AIDS, diabetes, cervical cancer and tuberculosis [35]. 'Radio Today' is a Private Limited Company owned by Radio Broadcasting FM (Bangladesh) Corporate Limited. 'Radio Today' is the first private FM radio and has coverage to the capital and other major cities. 'Radio Today' has collaborated with many public health awareness raising campaigns on AIDS, dengue, bird flu, breast feeding, breast cancer, arsenic pollution and smoking cessation through special talk shows and radio dramas. 'Radio Today' has also hosted a live coverage of the 'United States Agency for International Development' (USAID) health conference in Dhaka named, 'Interventions for Impact in essential obstetric and newborn care 'Make Every Mother and baby count' (3-6 May 2012). Radio programs like 'Better Health Better Life' (7th May 2013) was broadcast in partnership with USAID-BANGLADESH to raise awareness on maternal health and breast feeding. 'Radio Today' has eight broadcasting stations all over Bangladesh, reaching over 120 million people [36].

'Bangladesh Betar' (BB) is the only state-owned radio station that provides news and broadcasts awareness-raising campaigns. It covers almost 158 million people around the country. Although the trend is changing in many rural areas of Bangladesh, listening to radios is still common than watching television. Approximately $69 \%$ of the rural population listen to Betar programs on family planning, child and maternal health and family planning [37]. 'Bangladesh Television' (BTV) is the only state-owned television network in Bangladesh with $78 \%$ of the total program content covering population health issues. TV watching is an important driver of health behaviour in Bangladesh. TV watchers had lower fertility and higher maternal healthcare than non-watchers of family planning related TV shows in Bangladesh [38]. In rural areas, BTV is the biggest and sole provider of health information, such as vaccination and iodine deficiency [37]. From the 14 relay stations, almost 2 million televisions receive transmissions. BTV reaches $97 \%$ of the country's population. In terms of health advocates and convenors, 'Bill \& Melinda Gates Foundation (BMGF)' or simply known as The Gates Foundation, is a major private philanthropic organization established by Bill and Melinda Gates to promote healthcare, improve literacy rates and reduce poverty. In Bangladesh, the Gates Foundation sanctioned grants of USD 1.5 million to BRAC in 2017 for disaster management [39] and USD 1 million to International Centre for Diarrhoeal Disease Research, Bangladesh (ICDDRB) for treating diarrhoea in children. Worldwide, the Gates Foundation has contributed to saving 122 million lives of children, 400 million lives saved from neglected tropical diseases (NTD) and overall deaths decreased from 204,000 in 1990 to 142,000 in 2013 which was a $30 \%$ drop [40]. 


\title{
International Advanced Research Journal in Science, Engineering and Technology
}

\author{
Vol. 6, Issue 6, June 2019
}

The World Bank provides financial assistance to developing countries so that they can carry out development projects. Bangladesh has received about US \$29 billion in grants and interest-free credits since 1972 [41]. World Bank has set up Health Sector Development Program (HSDP) in Bangladesh so that the Government of Bangladesh (GOB) can improve coordination between public health stakeholders for maternal and child health, nutrition, HIV and refugee health to be implemented [42]. About 10,000 projects funded by the World Bank are helping millions of Bangladeshis.

World Health Organization (WHO) in Bangladesh provides technical assistance and support in strengthening the public health systems for better health research, leadership and capacity-building [43]. The organization is working in collaboration with the GOB and various public health research institutes to reduce the prevalence and incidence of TB, malaria, AIDS and reduce social, health and economic burden of communicable and non-communicable diseases as well as primary healthcare for pregnant women and newborns. For example, the development of a maternal health voucher scheme that is estimated to help provide 174,000 poor pregnant women with free maternal care for themselves and their newborn annually [44]. United States Agency for International Development (USAID) provides funds, technical support and training for the implementation of public health interventions. USAID franchise called 'Smiling Sun' has helped Bangladesh reduce maternal and child mortality by two-thirds. During the same period, USAID helped to significantly reduce malnutrition from $60 \%$ to $36 \%$ [45]. USAID provided over 46 million health service consultations and helped in saving the lives of 185,000 children and 8,000 mothers as of 2017 [46].

In Bangladesh, United Nations Children's Funds (UNICEF) mainly focuses on providing children with safe drinking water, balanced nutrition sources and proper hygiene so that they have good health. UNICEF Bangladesh is working on projects such as Newborn Health Campaign in collaboration with the Ministry of Health and Family Welfare (MoHFW) to raise awareness on essential newborn care, especially in rural and remote areas. National Nutrition Services Programme (NNS) aims to reduce malnutrition. WASH (Water, sanitation and hygiene) program helped lower chances of severe water and sanitation related diseases among 37,500 people, including 19,500 women [47]. Public Health Foundation of Bangladesh (PHFBD) is an independent and non-profitable organization, led by well-reputed researchers, clinicians, public health specialists and other multidisciplinary professionals who focus on health promotion, training, publishing newsletters, electronic journals and regular seminars. The Foundation holds free health camps, cancer awareness discussions, runs workshops and training programs for researchers and professionals. Currently, 63 members and over 100 volunteers are working on health awareness campaigns, reaching millions of people all over Bangladesh [48].

Dhaka Community Hospital Trust (DCH Trust) has been implementing an integrated and sustainable health care delivery system at an affordable cost in both the urban and rural areas of Bangladesh. Some examples are the DCH in collaboration with UNICEF-Bangladesh, United Nation Foundation (UNF)-United States of America (USA) and World Health Organization (WHO)-Dhaka that has developed an arsenic management protocol to screen all the family members of 1007 villages in order to identify arsenicosis patients. About 1.3 million populations of 210,000 families have been screened. Around 100,000 people received arsenic free safe water in arsenic affected areas of Bangladesh by the Arsenic Mitigation and Safe Water Program [49]. Muslim Aid Bangladesh has established healthcare programs like the 'Humanitarian Response, Recovery and Resilience' Program, 'Healthcare for mother and children' and 'Water Sanitation \& Hygiene (WASH)'. The main aims of community based health program include prevention and treatment of common illness; reduction of reproductive health disorder; and improvement in child mortality and morbidity. There are 873,761 total beneficiaries from all the programs. Muslim Aid Bangladesh aims to deliver high quality healthcare services at a low cost to some of the most vulnerable and isolated communities in 54 districts and 168 administrative regions [50].

The British Asian Trust funds sustainable development projects that focuses on poverty eradication, injustice and supports development impact bonds (DIBs) through philanthropy [51]. The British Asian Trust set up Bangladesh Youth Enterprise Advice and Help Centre (B'YEAH) to train unemployed youths and support small businesses with organizing loans. The British Asian Trust also funds programs regarding mental health; maternal health; water, hygiene and sanitation. They helped set up 'Wells for India' in Rajasthan. The Trust has impacted more than 4 million lives in places all over India, Pakistan, Sri Lanka and Bangladesh [51]. The Global Fund to fight AIDS, Tuberculosis and Malaria also known as The Global Fund supports innovative and cost-effective health programs aimed at TB patients and raising awareness and treatment for malaria and HIV patients in Bangladesh and other developing nations. A total of US\$486,044,742 has been invested for healthcare interventions [52]. In 2017, treatment was provided to almost 200,000 TB patients and 2,240,000 insecticide-treated mosquito nets were distributed to prevent malaria [53]. A report issued by The Global Fund in September 2018 showed that the organization saved 27 million lives altogether. In all the countries that the Global Fund invests, it was found that, 17.5 million people received antiretroviral therapy for HIV, 5 million people were tested and treated for TB and 197 million mosquito nets were distributed to prevent malaria [52]. 


\title{
International Advanced Research Journal in Science, Engineering and Technology
}

\author{
Vol. 6, Issue 6, June 2019
}

\section{DISCUSSION}

In Bangladesh, with a population of 166 million, almost 45 million poverty-stricken people struggle to pay healthcare costs. The 'Save a Million' (SaM) project is part of a decade-long plan and is still in the initial development stages. The main aim of the project is to look for health programs that save a million years of life (Disability-adjusted life years, DALYs) and reduce a million dollars by setting up several social impact bonds (SIBs).

\section{LIMITATIONS}

The greatest challenge was identifying potential 'savings programs' which could save life and cost for institutional cost-bearers for the chosen jurisdiction. As with many developing countries, it was difficult to find recent data since regular updates were not often made for various websites. For the same reason, there are limited available information from government reports.

\section{CONCLUSION}

From the 'Save a Million' project it is evident that there are three stakeholders: Savings Program Providers which are mainly NGOs; Institutional cost-bearers that include Ministry of Family and Health Welfare (MOFHW), public hospitals, insurance companies; and community health insurance providers. Besides, promoters and supporters also include print media, television, radio, philanthropy organizations, international organizations, trust funds and charity organizations. It is estimated that the six potential savings programs can avert 30 million DALYs approximately but cost per DALY averted is less than one million USD. It is also found that the estimated expenditure for the above mentioned potential savings programs is around USD 2 billion. The on-going 'Save a Million' research and its ultimate establishment can reduce this cost via multi-stakeholder funds. This can be one way to reduce the expenditure gap in private-public health service currently existing in Bangladesh.

\section{ACKNOWLEDGEMENT}

The authors sincerely wish to acknowledge Mr Alistair Gee, Honorary Lecturer at the Sydney School of Public Health, Faculty of Medicine and Health, The University of Sydney for developing the 'Save a Million' project concept and providing essential feedback in preparation of the paper.

\section{REFERENCES}

[1]. Joarder, T., Chaudhury, T., and Mannan, I. Universal Health Coverage in Bangladesh: Activities, Challenges, and Suggestions. Advances in Public Health. 2019; 2019(Article ID 4954095): 12. Available from https://www.hindawi.com/journals/aph/2019/4954095/

[2]. Global Health Data Exchange (GHDx). Institute for Health Metrics and Evaluation. Seattle, United States of America. [Cited 2019 Jun 22]. Available from http://ghdx.healthdata.org/gbd-results-tool?params=gbd-api-2016-permalink/131db70318786d31a83f3c256b7becb7

[3]. Bradford, L.Dey, B.Hussain, et al. Development of a cervical cancer screening program in a slum setting using visual inspection with acetic acid: Analysis of feasibility \& cost. Jour of Obstetrics \& Gynecology. 2012; 2: 140-146. Avail from http://dx.doi.org/10.4236/ojog.2012.22027

[4]. Raquib, T. Khan, S. Farooque, M. et al. Cervical cancer. AK Khan Healthcare Trust [Internet]. 2017, April, 25 [Cited 2019 Jun 18]. Available from http://akkhanhealthcaretrust.org/ 2017/04/25/cervical-cancer/

[5]. Campos, N. Sharma, M. Clark, et al. Comprehensive Global Cervical Cancer Prevention: Costs and Benefits of Scaling up with a Decade. [Report]. 2016, Jul 1; Boston, Massachusetts: Centre for Health Decision Science. Harvard School of Public Health. Available from https://www.cancer.org/content/dam/cancer-org/cancer-control/en/reports/the-cost-of-cervical-cancer-prevention.pdf

[6]. Uzzal, M.Affordable treatment for cervical cancer. Dhaka Tribune. 2014 Jan 15. Available from https://www.dhakatribune.com/uncategorized /2014/01/15/affordable-treatment-for-cervical-cancer

[7]. Holme, F. Kapambwe, S. Nessa and et al. Scaling up proven innovative cervical cancer screening strategies: Challenges and opportunities in implementation at the population level in low- and lower-middle-income countries. International Journal of Gynecology and Obstetrics. 2017; 138(S1): 63-68. Available from https://obgyn.onlinelibrary.wiley.com/doi/full/10.1002/ijgo.12185

[8]. BlueStar Bangladesh: The Center for Health Market Innovations. [Internet]. Results for Development Institute. [Cited 2019 Jun 21]. Available from https://healthmarketinnovations.org/program/bluestar-bangladesh

[9]. Grameen Healthcare [Internet]. Extending the Success of the Principles of Microcredit to Health Care Delivery. 2011 [Cited 2019 Jun 19]. Available from https://www.muhammadyunus.org/index.php/social-business/362-grameen-healthcare

[10]. BRAC Bangladesh Annual Report. Building a world that works for all of us. Dhaka: BRAC; 2016. Available from http://www.brac.net/ publications/annual-report/2016/

[11]. Gonoshasthaya Kendra (GK). The Center for Health Market Innovations. [Internet]. Results for Development Institute. [Cited 2019 Jun 21]. Available from https://healthmarketinnovations.org/program/gonoshasthaya-kendra-gk

[12]. Concerned Women for Family Development (CWFD). [Internet]. Results for Development Institute. [Cited 2019 Jun 21]. Available from https://healthmarketinnovations.org/program/concerned-women-family-development-cwfd

[13]. Sajida Foundation Health Program. The Center for Health Market Innovations. [Internet]. Results for Development Institute. [Cited 2019 Jun 21]. Available from https://healthmarketinnovations.org/program/sajida-foundation-health-program

[14]. Ahmed, S. and Islam, W. Costed Implementation Plan for the National Family Planning Programme, Bangladesh. [Internet]. Final Report; 2015. Available from https://www.familyplanning2020.org/sites/default/files/Bangladesh-CIP-2016-2020_0.pdf

[15]. Chisholm, D. Naci, H. Hyder, et al. Cost effectiveness of strategies to combat road traffic injuries in sub-Saharan Africa and South East Asia: mathematical modelling study. BMJ. 2012; 344:e612. Available from https://www.bmj.com/content/344/bmj.e612 


\title{
International Advanced Research Journal in Science, Engineering and Technology
}

\author{
Vol. 6, Issue 6, June 2019
}

[16]. Wesson, H. Boikhutso, N. Bachani, A. Hofman, K. Hyder, A. The cost of injury and trauma care in low- and middle-income countries: a review of economic evidence. Health Policy Plan. 2014; 29(6): 795-808. Available from https://www.ncbi.nlm.nih.gov/pubmed/24097794

[17]. National Road Safety Strategic Action Plan 2002-2004. Bangladesh National Road Safety Council. Ministry of Comm. Roads \& Railway Division. Bangladesh Road Transport Authority. [Internet]. The Government of the People's Republic of Bangladesh; 2004 [Cited 2019 Jun 23]. Available from http://www.rhd.gov.bd/Documents/ConvDocs/National\%20Road\%20Safety\%20Action\%20Plan\%202002-2004.pdf

[18]. Gomez, G. Dowdy, D. Bastos, et al. (2016). Cost and cost-effectiveness of tuberculosis treatment shortening: a model-based analysis. BMC Infectious Diseases. 16:726. https://doi.org/10.1186/s12879-016-2064-3

[19]. Lubell, Y. Yeung, S. Dondorp, et al. Cost-effectiveness of artesunate for the treatment of severe malaria. Journal of Tropical Medicine and International Health. 2009; 14(3): 332-337. Available from https://www.ncbi.nlm.nih.gov/pubmed/19187518

[20]. Hogan, D.Baltussen, R.Hayashi \& etal. Achieve the millennium development goal for health: Cost effectiveness analysis of strategie to combat HIV/AIDS in developing countries. BMJ. 2005; 1-7. Available from https://www.bmj.com/content/early/2004/12/31/bmj.38643.368692.68

[21]. Ortegón, M, Lim, S, Chisholm, D, Mendis, S. Cost effectiveness of strategies to combat cardiovascular disease, diabetes, \& tobacco use in subSaharan Africa \& South East Asia: mathematical modelling study. BMJ.2012;344:e607. Available from https://www.bmj.com/content/344/bmj.e607

[22]. Holloway, K. Bangladesh Pharmaceuticals in Healthcare Delivery [Draft Mission Report]. World Health Organization; 2010 Nov 30. Available from http://www.searo.who.int/entity/medicines/bangladesh_situational_analysis.pdf?ua=1

[23]. Molla, A. and Chi, C. Who pays for healthcare in Bangladesh? An analysis of progressivity in health systems financing. International Journal for Equity in Health. 2017; 16:167. Available from https://equityhealthj.biomedcentral.com/articles/10.1186/s12939-017-0654-3

[24]. Molla.M, Calling an ambulance? Don't bother. Dhaka Tribune. 2016 Jan 23. Available from www.dhakatribune.com/uncategorized/2016/01/23/calling -an-ambulance-dont-bother

[25]. Debnath, B. Ambulance Service. The Independent [Internet]. 2018 May 25 [Cit 2019 Jun 18]. Available from http://www.theindependentbd.com/magazine/details/151308/Ambulance-Services

[26]. Begum, F., Alam, S. and Hossain, A. Funds for Treatment of Hospitalized Patients: Evidence from Bangladesh. Journal of Health, Population, and Nutrition. 2014; 32(3):465-470. Available from https://www.ncbi.nlm.nih.gov/pmc/articles/PMC4221452/

[27]. Acharya, M. Adapt Pharmaceutic Pricing \& Reimbursement Strategy for Achieving Universe Health Coverage in Nepal: Lesson from Selected Low \& Lower Middle Income Countries. Indian Jour of Pharmaceutical Sciences. 2016;78(5):582-590. Available from http://www.ijpsonline. com/articles/adapting-pharmaceutical-pricing-and-reimbursement-strategies-for-achieving-universal-health-coverage-in-nepal-lessons-fr.pdf

[28]. Kumar S, Bano S. Comparison \& Analysis of Health Care Delivery System: Pakistan Vs Bangladesh. J Hosp Med Manage.2017,3:1. Available from http://hospital-medical-management.imedpub.com/comparison-\&-analysis-of-health-care-delivery-system-pakistan-Vs-bangladesh.php?aid=18097

[29]. Islam, A., Akhter, S. \& Islam, M. Health Financing in Bangladesh: Why Changes in Public Financial Management Rules Will Be Important. Health Systems \& Reform. 2018; 4(2):65-68. Available from https://www.tandfonline.com/doi/full/10.1080/23288604.2018.1442650

[30]. Ahmed, S. Alam, B. Anwar, I. et al. Bangladesh Health System Review. Health Systems in Transition. 2015; 5(3). Available from http://apps.searo.who.int/PDS_DOCS/B5409.pdf

[31]. Palma, P. Health sector uncared for. The Daily Star. 2018 Jun 8. Available from https://www.thedailystar.net/frontpage/2018-19-bangladeshbudget-health-sector-uncared-1588216

[32]. Kallol, A. Families to get medical, festival allowances even after death of recipient. Dhaka Tribune. 2017 Aug 7. Available from https://www.dhakatribune.com/bangladesh/2017/08/07/families-get-medical-festival-allowances-even-death-recipient

[33]. Pragati Life Insurance Ltd. [Internet]. Dhaka, Bangladesh; 2015 [Cited 2019 Jun 19]. Available from https://www.pragatilife.com/index.php

[34]. Gugsa, F, Karmakar, E, Cheyne, A, \& Yamey, G. Newspaper coverage of maternal health in Bangladesh, Rwanda \& South Africa: a quantitative \& qualitative content analysis. BMJ Open2016;6:e008837. Available from https://bmjopen.bmj.com/content/bmjopen/6/1/e008837.full.pdf

[35]. No room for complacency in health care. Prothom Alo. 2018 Jun 4. Available from https://en.prothomalo.com/opinion/news/176998/No-roomfor-complacency-in-health-care

[36]. Currie, S. de Graft-Johnson, J. Galloway, et al. Interventions for Impact in Essential Obstetric and Newborn Care [Meeting Report]. 2012; Dhaka, Bangladesh. Available from https://www.healthynewbornnetwork.org/hnn-content/uploads/EONC_AsiaRegionalMeeting_web.pdf

[37]. Hasan, S. and Baten, A. Role of Mass Media in Promotion of Family Planning in Bangladesh. Journal of Applied Sciences. 2005 ; 5: $1158-1162$. Available from https://scialert.net/fulltextmobile/?doi=jas.2005.1158.1162

[38]. Rahman, M. Curtis, S. Chakraborty, N. Jamil, K. Women's television watching and reproductive health behavior in Bangladesh. Journal of Population Health. 2017; 3:525-533. Available from https://www.sciencedirect.com/science/article/pii/S2352827317301416

[39]. BRAC. BRAC receives USD 1.5 million from Bill \& Melinda Gates Foundation [Internet]. Dhaka; 2018 [updated 2018 Apr 11; cited 2019 Jun 19]. Available from http://www.brac.net/latest-news/item/1146-brac-receives-usd-1-5-million-from-bill-melinda-gates-foundation

[40]. Andrews, R. We spoke to Bill Gates about Saving 400 million people from Disease: "All Life Has Equal Value". IFL Sci. (2017 Apr 22 ). Available from https://www.iflscience.com/health-and-medicine/we-spoke-to-bill-gates-about-saving-400-million-people-from-disease-all-life-has-equal-value/all/

[41]. The World Bank. World Bank helps Bangladesh Improve Primary Education, National Statistics [Press Release]. 2018 Jun 28. Available from https://www.worldbank.org/en/news/press-release/2018/06/28/world-bank-helps-bangladesh-improve-primary-education-national-statistics

[42]. Giuffrida, A. Implementation Completion Report (ICR) Review. Dhaka, Bangladesh. 2017 May $26 . \quad$ Available from http://documents.worldbank.org/curated/en/114181528922648368/pdf/Bangladesh-BD-Health-Sector-Development-Program.pdf

[43]. World Health Organization (WHO). [Internet]. About WHO in Bangladesh; (2019). [Cited 2019 Jun 21]. Available from http://www.searo.who.int/bangladesh/about/en/

[44]. World Health Organization . Country Office for Bangladesh . (2010). WHO collaboration in Bangladesh: biennial report 2008-2009. World Health Organization. Country Office for Bangladesh.

[45]. Lance P., Angeles G, Kamal N. Smiling Sun Franchise Program (BSSFP). Impact Evaluation Report. Chapel Hill, North Carolina: MEASURE Evaluation; 2012. Available from https://www.measureevaluation.org/resources/publications/tr-12-89

[46]. USAID. [Internet]. Bangladesh Country Profile; [ 2018 Jul 16]. Available from https://www.usaid.gov/sites/default/files/documents /1861/BANGLADESH_COUNTRY_PROFILE_JULY_2018.pdf

[47]. UNICEF Annual Rep. Executive Sum. Bangladesh; 2017. Available from https://www.unicef.org/about/annualreport/files/Bangladesh_2017_COAR .pdf

[48]. WHO Public health foundation of Bangladesh (PHFBD). [Internet]; (2018) [cited 2019 Jun 20].Available from https://www.who.int/workforcealliance/members_partners/member_list/phfb/en/

[49]. Dhaka Community Hospital Trust (DCH Trust). [Internet]. Dhaka, Bangladesh; 2018 Nov 1 [2019 Jun 19]. Available from https://dchtrust.org/ [50]. Muslim Aid [Internet]. Muslim Aid-UK, Bangladesh Country Office; 2018 Dec 4 [2019 Jun 21]. Available from http://www.muslimaid.org.bd/

[51]. British Asian Trust. [Internet]. United Kingdom; 2016 [Cited 2019, Jun 20]. Available from https://www.britishasiantrust.org/who-we-are/about

[52]. The Global Fund to Fight AIDS, Tuberculosis and Malaria. Global Fund Partnership has Saved 27 Million Lives [Internet]; 2018 Sept 12 [Cited 2019 Jun 19]. Available from https://www.theglobalfund.org/en/news/2018-09-12-global-fund-partnership-has-saved-27-million-lives/

[53]. The Global Fund to Fight AIDS, Tuberculosis and Malaria [Internet]. Cited 2019 Jun 21. Available from https://www.theglobalfund.org/en/ 